\title{
Local Attitudes on Protected Areas: Evidence from Sumava National Park and Sumava Protected Landscape Area
}

\author{
Tomas Gorner ${ }^{1,2} \&$ Martin Cihar ${ }^{1}$ \\ ${ }^{1}$ Institute for Environmental Studies, Faculty of Science, Charles University, Prague, Czech Republic \\ ${ }^{2}$ Agency for Nature Conservation and Landscape Protection, Prague, Czech Republic \\ Correspondence: Tomas Gorner, Agency for Nature Conservation and Landscape Protection, Kaplanova Street, \\ Prague 14800, Czech Republic. Tel: 420-283-069-237. E-mail: tomas.gorner@nature.cz
}

\author{
Received: December 3, 2012 Accepted: January 23, 2013 Online Published: March 5, 2013 \\ doi:10.5539/ep.v2n2p1 \\ URL: http://dx.doi.org/10.5539/ep.v2n2p1
}

\begin{abstract}
The present article aims to describe perceptions and awareness of local residents in two categories of the Sumava region protected areas-National Park (NP) and Protected Landscape Area (PLA). The survey explores perceptions of individuals on nature protection, protected area management, tourism and related issues. Differences between these two research areas are also explored. Standardised personal interviews were conducted during the summer season of 2008. The study took place in six municipalities in NP (Borova Lada, Srni, Prasily, Kvilda, Horska Kvilda and Modrava; 183 questionnaires in total) and in three municipalities in PLA (Kasperske Hory, Hojsova Straz and Cachrov; 138 questionnaires in total). According to the results of the study, there were more natives and indigenous residents in NP than PLA. Similarly, local people in NP were working more often in the public sector and less in the private sector and they had more benefits from tourism. Residents in PLA were less informed about Administration activities, more satisfied with topical nature conservation level and against expansion of NP to their place of residence. Also, a significant finding of the study is that residents (especially in PLA) were supportive of some forms of participatory management. They are interested in the advancement of the area, mostly in the form of improvement of tourism-related facilities. They love this region and also call for better communication with NP/PLA Administration.
\end{abstract}

Keywords: sustainable tourism and management, monitoring, local people, protected areas

\section{Introduction}

Protected areas (national parks, landscape areas, nature reserves, etc.) represent the most widely accepted means of biodiversity conservation on a national and international level (Sekhar, 2003). Local communities could be affected by the creation of protected areas due to restricted use of local resources. This is a problem particularly in developing countries (loss of access to resources-fuelwood, fodder, etc.), but also in other countries (constraint on land use and management practices-agriculture, fishing and hunting) (Brandon, Gorenflo, Rodrigues, \& Waller, 2005). Thus, conservation activities and management have frequently conflicted with local community attitudes, needs and desires (Bartlett, Maltali, Petro, \& Valentine, 2010). In many cases, the "top-down" approach is used-protected areas and their conservation strategies are established without consultation of the local people. But in order to reach sustainable development in these areas it is necessary to value people's attitudes and knowledge and give them the opportunity to express their opinions on management of protected areas. Therefore, the term participation is used (Pimbert \& Pretty, 1997). This "bottom-up" approach means that local communities and agencies are actively involved in the decision-making process (Wallner, Bauer, \& Hunziker, 2007). Local people, especially those living in the protected areas, have important and long-standing relationships with these localities. Thus, their needs and attitudes should be taken into account by management of these areas (Xu, Chen, Lu, \& Fu, 2006). Studies dealing with attitudes of participants may improve protected area management, and help to identify the problems and to recognise potential solutions for appropriate developing strategy (Sewell, 1973). Most common factors affecting residents' perceptions are the level of trust towards institutions responsible for environmental management (Kim, 2009), the changes imposed during the designation of a protected area (Garcia-Frapolli, Ramos-Fernandez, Galicia, \& Serrano, 2009) and the level of awareness among citizens (Petrosillo, Zaccarelli, Semeraro, \& Zurlini, 2009).

In the Czech Republic, there are two categories of protected areas, where the abovementioned conflicts could 
occur. The strictest level of conservation applies to national parks. These are defined in Act No. 114/1992 Coll. on the protection of nature and landscapes as "extensive territories, unique on a national or international scale, a considerable part of which is covered by natural ecosystems or ecosystems little effected by human activities, where plants, animals, and abiotic nature are of an exceptional scientific and educational importance". According to the International Union for Conservation of Nature (IUCN), Czech national parks (except Krkonose NP) belong to Category II National Parks (IUCN 1994). The second category, protected landscape areas (PLA), are defined in the Act as "extensive territories with a harmoniously formed landscape, a characteristically developed relief, a significant proportion of natural ecosystems of forests and permanent grasslands, with abundant presence of woody plants, or, optionally, with preserved monuments of historical settlement" (Act No. 114/1992). PLA in the Czech Republic fall into the IUCN Category V Protected Landscape (IUCN 1994).

Most of the sociological studies in protected areas of the Czech Republic are focused on visitors and their quantitative (amounts) and qualitative (questionnaires) monitoring (e.g. Cihar \& Trebicky, 1997; Cihar, Stursa, \& Trebicky, 2002; Stursa, 2002; Suchy, 2002). The monitoring of local communities in Czech protected areas is located mostly in the national parks and Biosphere Reserves (Cihar \& Stankova, 2006; Kusova, Tesitel, Matejka, \& Bartos, 2008). Other studies cover several types of protected areas; Cudlinova, Lapka, and Bartos (1999) monitored the attitudes of farmers in the whole Sumava region, which includes Sumava NP, Sumava PLA and unprotected areas in the foothills. Bartos and Cihar (2011) conducted a survey amongst the inhabitants of the Sumava NP and in the closely located Nove Hrady Mountains, an area designated as a Nature Park. Nevertheless, these studies were focused primarily on regional differences but not on another level of nature protection of these areas.

The aim of this paper is monitoring of residents' characteristics in Sumava NP and PLA. This is the first study in the Czech Republic that is primarily focused on local people in neighbouring protected areas that differ from the level of nature protection. Most previous sociological studies in this area took place only in NP, as a well-known and traditional tourist destination. Nevertheless, PLA is much more populated (21000 inhabitants apart from 1000 residents in NP) and local nature protection regime influences more people in their daily lives. Characteristics and attitudes of PLA residents could be slightly or significantly different from their neighbours in NP. This paper compares these two protected areas from residents' points of view and describes the variations and their reasons.

\section{Material and Methods}

\subsection{Study Area}

The first colonisation of the Sumava region dates back to the end of the twelfth century. Up to the eighteenth century, the whole area was covered by virgin primeval forests forming a part of the boundary woodland. Later colonisation linked to the development of glass manufacture, logging and pasturing played an important part in creating the current ecosystems (disappearance of primeval forests, establishment of new settlements, preference of spruce monocultures in artificial planting, forest calamities, continuing grazing on vast meadows).

Before and after the Second World War, the region was affected by major political changes that considerably influenced the structure, number and social composition of the local population. The region was part of the Sudetenland, located on the Czechoslovakian border with Germany and Austria, which had a majority of ethnic German inhabitants. This area was incorporated into the Reich in 1938. At the end of the war, Germans were subjected to restrictive measures and by the end of 1946, some 1.7 million Germans had been resettled. The current inhabitants represent only $12 \%$ of the original population of 1930 (Kusova, Bartos, \& Tesitel, 1999). After February 1948, radical Communists took power. The establishment of the 'Iron Curtain' between Western Europe and Communist Eastern Europe, and the associated military training areas in Sumava, increased the isolation of the region. People live less than $2 \mathrm{~km}$ from the border were resettled from this area, while residents living in the $6 \mathrm{~km}$ buffer zone (area of current NP) from the border were heavily restricted in their movements. The situation far from the border (area of current PLA) was more favourable for those staying there. Nevertheless, the settlement of the Sumava region in this time was similar to the conditions in the fifteenth and sixteenth centuries (Kluvankova-Oravska, Chobotova, Banaszak, Slavikova, \& Trifunovova, 2009; Kusova et al., 1999).

In 1989, the Velvet Revolution introduced democratic changes in Czechoslovakia, opening borders and resulting in completely new opportunities: Sumava became a popular tourist destination and underwent intensive socio-economic development. This fast transition from a state-planned to a free market economy created tensions regarding sustainable development programmes in the region (Cihar \& Stankova, 2006). At present, the Sumava region is facing both the positive and negative effects of tourism. Thus, the main goal for management today is 
to balance this impact in cooperation with the local inhabitants.

In 1963, an area of $1687 \mathrm{~km}^{2}$ was designated as the Sumava Protected Landscape Area (PLA). In 1990, this area was added to the UNESCO list of Biosphere Reserves (BR). One year later, the most valuable part of PLA along the border with Germany and Austria was decreed a National Park $\left(690 \mathrm{~km}^{2}\right)$, considered the highest (and strictest) legal measure of natural protection in the Czech Republic. PLA and NP have a joint administration body-the Administration of the NP and PLA.

\subsection{Monitoring of Local People}

The first research was carried out in Sumava NP in summer 1998 and its main aim was to collect basic data on local people's acceptance of the newly established Sumava NP. This was perhaps the first time that the residents of the Sumava National Park and Biosphere Reserve had had an opportunity to express their opinions and perceptions of management and policies in the area (Cihar, Trebicky, \& Stankova, 2008). The research was repeated in August 2003 and 2008 with identical questionnaires.

This study used the results from the monitoring in 2008. The sample consisted of residents from six villages within the central-western part of the Sumava NP (Kvilda, Horska Kvilda, Modrava, Srni, Prasily and Borova Lada). The population of all six villages was around 1.000 (Czech Statistical Office [CZSO], 2003). The questionnaire consisted of 30 questions, which were divided into five thematic parts: demographic characteristics, place attachment, environment and nature in the area, evaluation of the NP/PLA management and development of tourism. Open, closed, semi-open, alternative, selective and scale questions were used. The questionnaire survey was administered through personal interviews in randomly selected households. Method of random route sampling was used. After arrival to village it was selected left or right part along the main road by lot and consequently it was by lot selected number from one to the five and then it was visited every nth (first to fifth) address and if the person answering the door met the conditions of the survey, he or she was interviewed. To avoid any influence of attitudes from other members of the family, every attempt was made to hold a face-to-face interview with the respondent separately.

In order to compare the characteristics and attitudes of locals in neighbouring protected areas, research using an identical questionnaire was carried out in three villages (Kasperske Hory, Hojsova Straz and Cachrov) in PLA in the same period (August 2008)-see Figure 1.

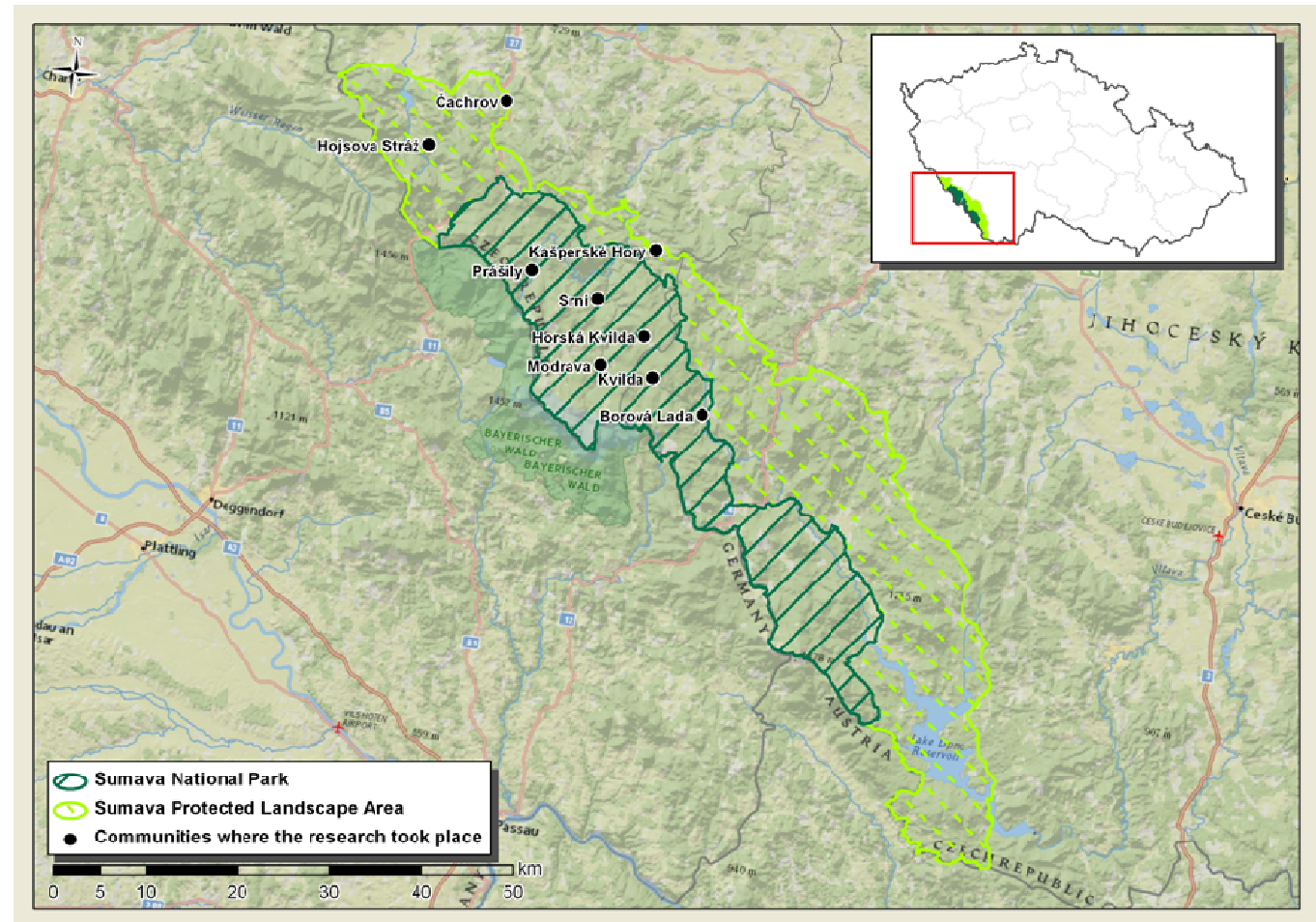

Figure 1. Map of the Sumava National Park and the Sumava Protected Landscape Area 
All completed questionnaires were processed in the form of database files using Microsoft Access. The frequencies and results of filtering were also transferred to MS Excel, in order to create the tables and charts. Statistical Programme SPSS, version 16.0 was used for statistical evaluation of these data. We used the chi square test $\chi^{2}$ at the significance level of 0.05 (Freund \& Wilson, 2003) for evaluating cases where results differed between two categories of protected areas.

\section{Results}

The total samples consisted of 183 questionnaires from NP municipalities (17.3\% of all residents) and 138 from PLA $(0.7 \%$ of all residents). Only permanent residents completed the questionnaires. Weekenders, long-term visitors and seasonal workers were excluded. The response rate was $83.6 \%$ in NP and $84.8 \%$ in PLA. All hodnocenych questions are summarized in Table 1.

Table 1. Comparison of characteristics and attitudes of NP and PLA residents (chi square test $\chi^{2}$ at the significance level of 0.05)

\begin{tabular}{lll}
\hline & Difference & p value \\
\hline Age group & yes & 0.021 \\
Gender & no & 0.448 \\
Education & no & 0.683 \\
Employment (private x public sector) & yes & 0.000 \\
Occupational groups & no & 0.061 \\
Residents/weekenders ratio & no & 0.159 \\
Resident since birth & yes & 0.001 \\
Reasons to move to the area & no & 0.240 \\
Generation ties to the area & yes & 0.000 \\
Place attachment & yes & 0.000 \\
Willingness to move & yes & 0.000 \\
Identifying an environmental problem & no & 0.947 \\
Evaluating of the state of the environment & yes & 0.000 \\
Identification of local problems & yes & 0.000 \\
Evaluating the existence of protected area & - & - \\
Evaluating of nature protection regime & yes & 0.009 \\
Attitudes to the access to disputed regions & yes & 0.009 \\
Type of regulated access to these areas & yes & 0.000 \\
Evaluation of NP/PLA Administration office as: & & \\
$\quad$ - administration office & yes & 0.000 \\
$\quad$ - organisation managing natural resources & yes & 0.034 \\
$\quad$ - educational institution & yes & 0.000 \\
Evaluation of communication among municipalities & yes & 0.007 \\
and Administration & & \\
Trends in the amount of tourists in the NP/PLA & no & 0.579 \\
Carrying capacity on the hiking trails & no & 0.146 \\
Carrying capacity in the centres & yes & 0.000 \\
Opinions about influence of tourism on the local & yes & 0.000 \\
prices & yes & 0.000 \\
Economic profit from the tourism industry & yes & 0.000 \\
Job opportunities in the region & yes & 0.000 \\
Influence of the NP/PLA on the job opportunities & yes & 0.000 \\
\hline
\end{tabular}

\subsection{Sociodemography}

The first thematic block in the questionnaire deals with the socio-demographic characteristics of the respondents. Significant differences were detected only in the age group of residents $(p=0.021)$. In both protected areas the majority of respondents were people between 40 and 59 years followed by the 25-39 age group. Young people aged 18-24 years had a higher representation in PLA (18.1\%) compared with NP (8.7\%). As regards education and occupation, there was no significant difference between the groups. However, the survey detected significant variance in employment in the private/public sector $(p=0.000)$ : $65.9 \%$ of PLA respondents were employed in the 
public sector and $34.1 \%$ in the private sector, while in NP only $25 \%$ were public sector workers and $75 \%$ employed in the private sector. In order to compare, the results from the 1998 (52.9\% in the public sector and $47.1 \%$ in the private sector) and 2003 (45.2\% vs. 54.8\%) survey in NP municipalities are mentioned (Najmanova, 2004). These show the positive trend in private sector employment in NP, primarily due to tourism services development.

\subsection{Place Attachment}

In the NP survey, $79.8 \%$ of residents, $17.5 \%$ of weekenders and $2.7 \%$ of "others" were questioned. This was similarly the case in neighbouring PLA: $84.1 \%$ locals, $10.9 \%$ weekenders and 5.1\% "others". In total, 69\% of locals in NP were born in this area compared with $49 \%$ of residents in PLA. This significant difference $(p=0.001)$ does not correspond very much to the historical development of this place. Most of the municipalities in NP were almost uninhabited and again settled after 1989. The previous two surveys (1998 and 2003) detected in these municipalities $24.4 \%$ and $26 \%$ of natives (Najmanova, 2004). Similar monitoring of the Institute of Landscape Ecology ASCR revealed that the proportion of natives was 35.8\% (Tesitel, 2005). The markedly higher proportion of natives in this study could be the result of the growing population of the new Sumava generation.

The most frequently mentioned reasons for moving to the Sumava NP were marriage or family ties and other reasons (both 28.2\%) and desire to live in a natural environment (25.6\%). In PLA the most frequent answer was other reasons $-41.5 \%$ (the most common replies from this category were job opportunities and change of housing status from weekend-housing to permanent residence)-followed by desire to live in a natural environment $(21.5 \%)$ and inheritance $(18.5 \%)$.

More frequent ancestral links were detected in NP where $54.4 \%$ of residents had ancestral connection to the region as opposed to $48.6 \%$ in PLA. But this area showed significantly $(p=0.000)$ longer generation ties-see Figure 2. This could be the reason for stronger place attachment in the question "Do you perceive this area as home?"; $82.6 \%$ of PLA residents answered "absolutely yes" (as opposed to $42.6 \%$ in NP), $12.3 \%$ said "relatively yes" (47\% in NP), 1.4\% expressed a negative attitude (compared with $6 \%$ in NP) and 3.6\% (NP: $4.4 \%$ ) did not know. For $89.8 \%$ of people in PLA municipalities emigration from the park was not an option, even if they had opportunities to do so. Only $5.1 \%$ of them said that they would be prepared to move elsewhere and $5.1 \%$ did not know. Proportional representation in this question among NP residents was followed (categories in the same sequence): $75.5 \% / 16.2 \% / 8.4 \%$.

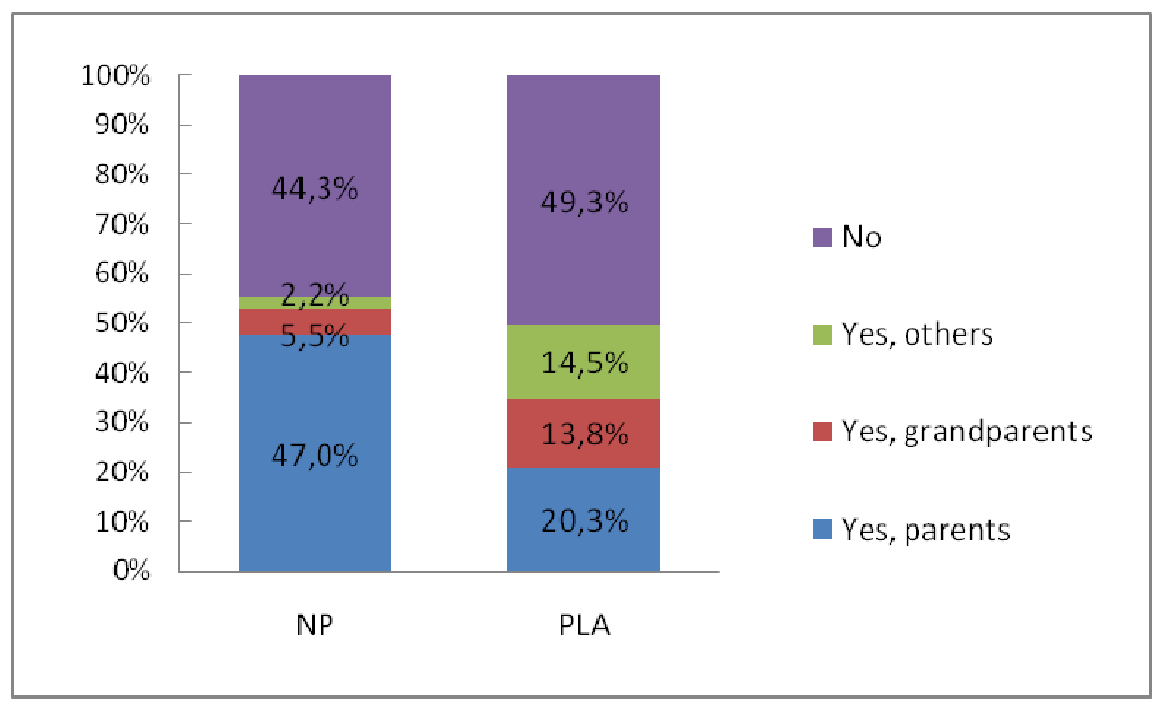

Figure 2. Have your ancestors lived in this area? 


\subsection{Environment and Nature in the Area}

The majority of respondents in both protected areas know about an environmental problem $(78.6 \%$ in NP and $78.3 \%$ in PLA). The most frequently mentioned environmental problems in NP were bark beetle (Ips typhographus), the condition of the forests, intensive logging and mass tourism. People in PLA stated bark beetle, the condition of the forests and solid waste management and disposal. One of the questions in this section concerned the state of the environment during the last 10 years (see Figure 3). Almost one half of PLA residents thought that the state of the environment improved between 1998 and 2008, while a third of them stated the opposite, and according to $18 \%$ of respondents the state of the environment had remained unchanged. The latter opinion was the most frequent answer among the NP residents $(39.9 \%)$ and especially due to this fact both groups (PLA x NP) showed a significant difference in this question $(p=0.000)$.

In order to identify local problems, respondents were asked to choose, from a list, one problem deserving the greatest attention and one problem deserving the least attention. In NP, the most crucial problems were as follows: the condition of the forests (45.4\%), the development of the infrastructure $(33.3 \%)$ and waste management $(7.7 \%)$. The problems deserving the least attention were: air quality $(48.6 \%)$, water quality $(29.6 \%)$ and public transport $(6.7 \%)$. In PLA, the most crucial problems were very similar: the condition of the forests $(41.2 \%)$, the development of the infrastructure (14.0\%) and waste management (13.2\%). Differences were detected in problems deserving the least attention: public transport $(26.7 \%)$, mass tourism (15\%) and air quality $(13.3 \%)$.

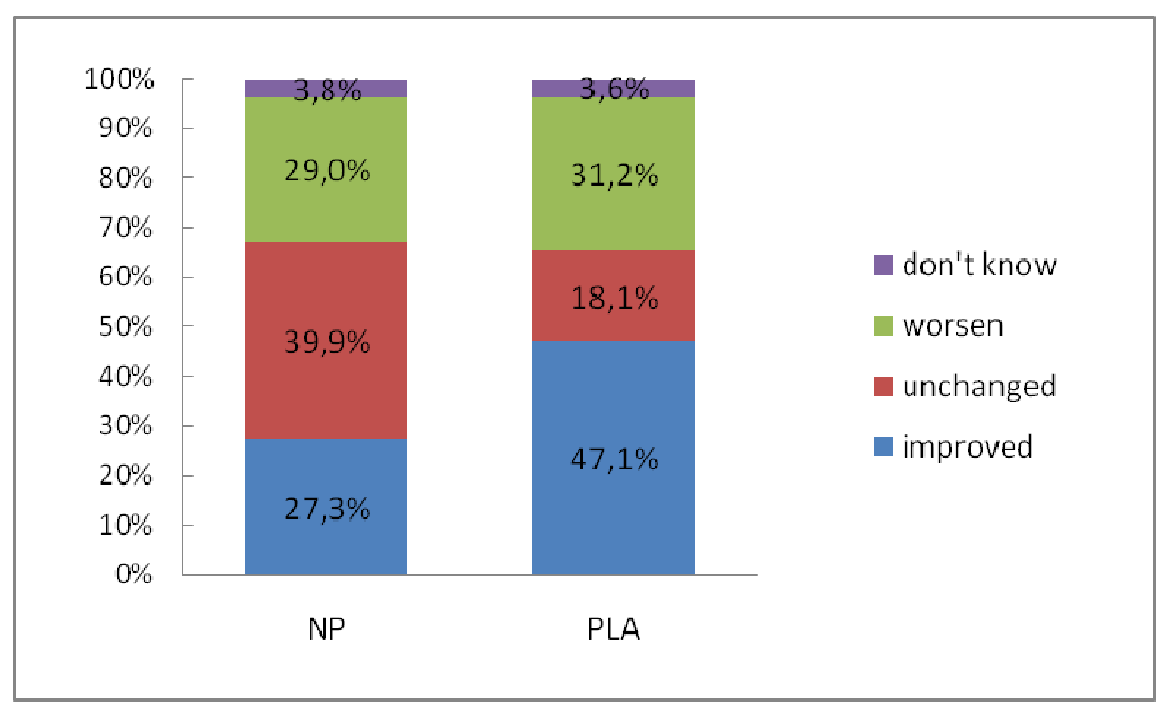

Figure 3. Evaluation of the state of the environment during the last 10 years

\subsection{Evaluating the NP/PLA Management}

Residents in NP/PLA evaluated the existence of a protected area where they lived. This study detected more positive reactions in NP than in PLA: 17.6\% of NP residents perceived this protected area as "positive" and 51.1\% as "rather positive"; "negative" opinion was detected by $2.7 \%$ of local people and $25.3 \%$ held "rather negative" attitude towards the existence of NP. People in PLA perceived this protected area in the following way: 7.2\% "positive", 23.9\% "rather positive", $42.8 \%$ "neutral", 10.9\% "rather negative" and 13\% "negative". These results were closely connected to economic benefits. More people were involved in tourism and profited from the existence of a national park. This question was not statistically evaluated due to the absence of the category "neutral" in the NP questionnaire. Respondents in PLA also more frequently thought that the current state of nature conservation is too strict (23.9\% compared with $11.5 \%$ in NP). The majority of PLA respondents thought that the current state of nature conservation is satisfactory (33.6\% against $32.2 \%$ in NP), $18.7 \%$ of the same group answered that it is "rather strict", 7.5\% that it is "rather soft", $5.2 \%$ it is "too strict" and $11.2 \%$ of the same group either did not have an opinion or did not want to answer. To compare with the remaining answers of NP respondents see Figure 4 . The difference in this question was statistically significant $(p=0.009)$. 


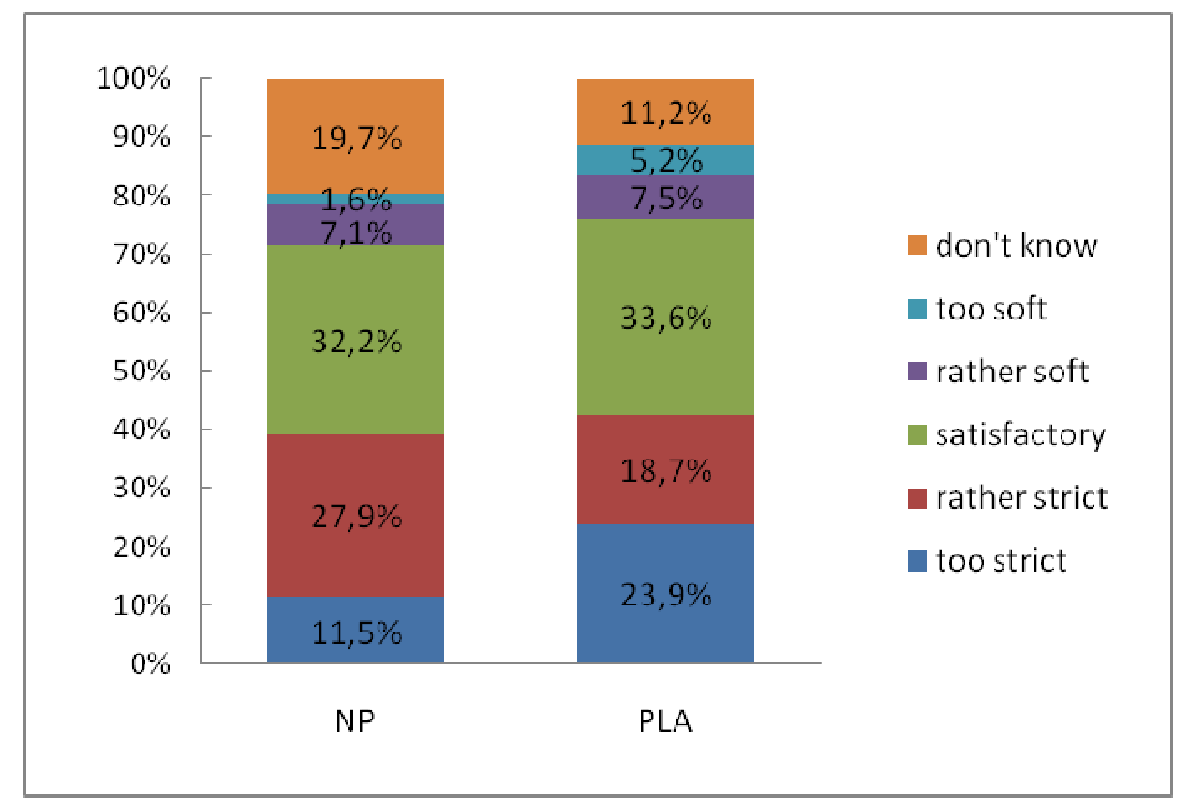

Figure 4. Evaluation of the current state of nature conservation in the NP/PLA

NP respondents more frequently stated that access to the disputed regions should not be made possible $(60.1 \%$ vs. $39 \%$ in PLA; $p=0.009$ ). In the case of regulated access of tourists to such natural areas, they would give preference to "access with a guide" $(55.9 \%)$, followed by "introduction of a fee" $(23.5 \%)$, "time-limited access" (20.1\%) and "other form of regulation" (0.6\%). A smaller section (47.8\%) of the PLA respondents thought that access to the places with most endangered environment "should probably be allowed" or "should be allowed without restrictions". In the case of regulated access of visitors to such natural areas, they would give preference to "access with a guide" (50\%), followed by "time-limited access" (38.1\%), "introduction of a fee" $(9.7 \%)$ and "other way of regulation" (2.2\%). Significant difference in this question was also detected $(p=0.000)$.

This study also evaluated the administrative and management activities of the NP and PLA Administration (one institute for both protected areas). We used a more specific set of questions to evaluate three different areas of the NP Administration's activities: the Administration as an educational institution, an organisation managing natural resources and an administration office. Residents of municipalities in NP were more satisfied with the NP Administration in all three categories. Figure 5 shows detailed results. They also less frequently used the answer "do not know" in this issue. People living in NP were better informed about NP Administration activities (close communication, the existence of information centres in NP). In comparison with PLA, a larger number of NP inhabitants were employed as NP Administration workers. Residents in PLA often complained about insufficient communication among municipalities and Administration (sufficient communication 3.6\%, insufficient 32.8\%, do not know $63.5 \%$; compared with $13.7 \%$ sufficient residents in NP, 33\% insufficient and $53.3 \%$ do not know) $-p=0.007$. People in PLA would also appreciate if a periodic report about Administration activities were issued. 


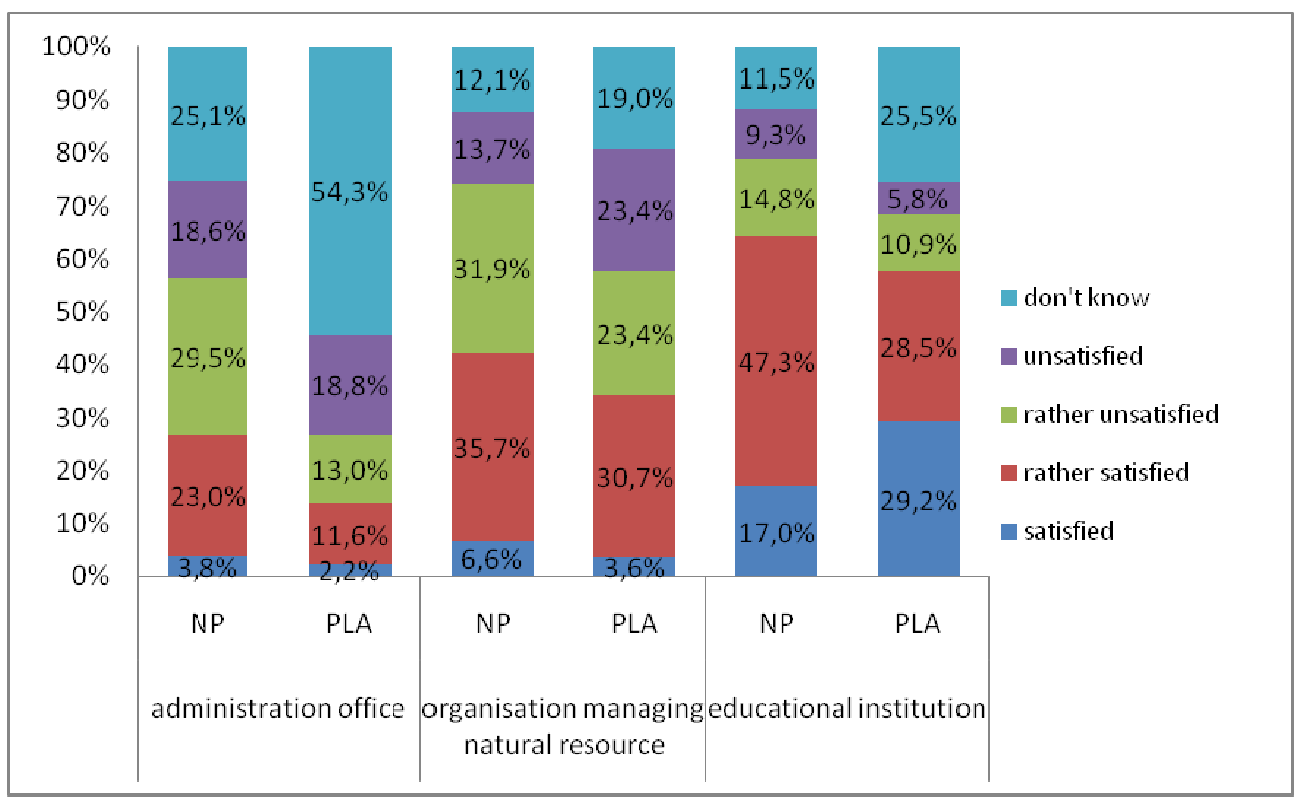

Figure 5. Evaluation of NP and PLA Administration as an educational institution, an organisation managing natural resources and an administration office

\subsection{Development of Tourism}

According to the majority of Sumava respondents (40.1\% in NP and $41.2 \%$ in PLA), the numbers of visitors in the region approximately around the time of the survey were increasing rapidly or moderately; $38.5 \%$ of respondents in NP and $32.4 \%$ in PLA stated that the amount of visitors remained the same. Only $11 \%$ of respondents in NP (and 12.5\% in PLA) thought that tourism decreased in these areas. These statements corresponded to the real amount of visitors in Sumava region. According to Statistical yearbooks of NP Administration, the attendance increased between 2000 and 2006 from 1.85 million visitors/year to 2.5 millions. Since that time the amount of visitors has been decreasing. The monitoring was carried out in 2008 so it did not reflect this trend.

Locals were asked how they perceived the intensity of tourism in the NP/PLA. The aim of this question was to determine the social carrying capacity of the destination from a local point of view. Results showed that the respondents $(81.9 \%$ in NP and $87 \%$ in PLA) were not concerned about visitor levels on the hiking trails. Different responses $(p=0.000)$ between NP $(63.7 \%)$ and PLA $(90.5 \%)$ were identified regarding visitor levels in the proximity of the respondent's place of residence. Looking at the negative responses, locals in NP seemed to be more concerned about visitor levels in the proximity of their places of residence $(36.2 \%)$ than those on the hiking trails (18\%). The situation in PLA was quite the opposite; $9.4 \%$ of residents found the tourism intensity near their residences disturbing and $13 \%$ of them perceived the tourism intensity on hiking trails as annoying. Locals in PLA also more frequently wished the tourism intensity could increase. If we compare results from this question with the monitoring of visitors' attitudes, surprisingly, more visitors than locals perceived the intensity of tourism as high and disturbing (Gorner \& Cihar, 2012).

According to NP respondents, the presence of tourists more likely (52\%) or definitely (43.6\%) raises their cost of living in comparison with other regions. According to PLA respondents, the presence of tourists more likely $(28.9 \%)$ or definitely $(28.9 \%)$ raises their cost of living in comparison with other regions. More in Figure 6.There was a significant difference in the answers to this question between the two groups $(p=0.000)$. This study also detected differences in local involvement in the tourism industry. Respondents in both protected areas were questioned as to whether they had made any profit from tourism $(p=0.000)$. One third of the NP respondents and only $13 \%$ of locals in PLA had made an economic profit from the tourism industry; $61.7 \%$ of people in NP and 79.6\% PLA residents had no profit from tourism. The remaining respondents $(4.9 \%$ in NP and $7.4 \%$ in PLA) had some profit from tourism, but they were not employed in this sector (e.g. pension owner who worked as a clerk). 


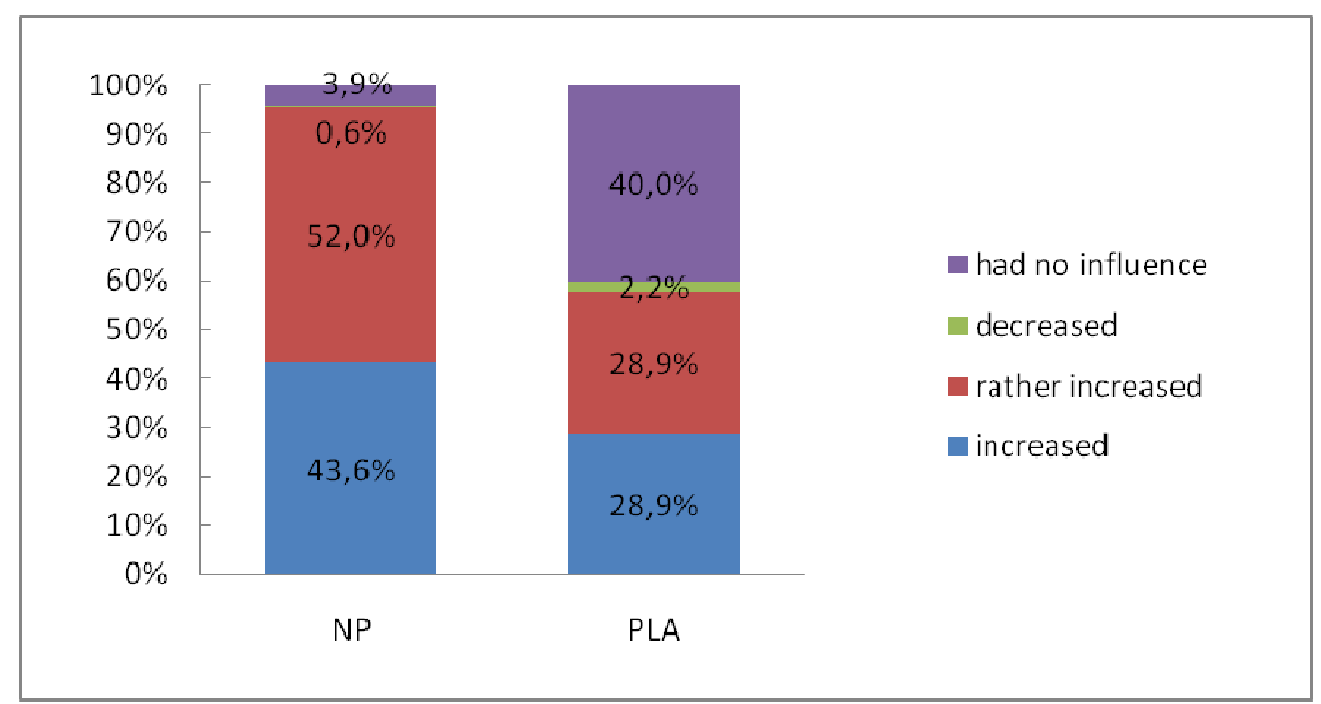

Figure 6. Residents' opinions about influence of tourism on the local prices in Sumava NP/PLA

The next question examined the availability of job opportunities in the region. This availability was assessed as "very insufficient" by $25.1 \%$ in NP (49.3\% in PLA) and as "rather insufficient" by $47 \%$ in NP $(31.2 \%$ in PLA). Only $15.3 \%$ of NP residents and $1.4 \%$ (!) of respondents in PLA were satisfied with job opportunities in the region ( $p=0.000$ in this question). In the next item, respondents were asked whether the designation of the area as an NP has affected job opportunities. NP residents perceived the NP as a source of job opportunities due to higher employment in the tourism industry (which is closely connected to the existence of this type of protected area). Opposite to this, people in PLA felt quite offended by the existence of the NP. Many of them lost their job when the National Park was designated because forest management had totally changed and many of the forest workers were dismissed. At the end of our questionnaire we included a question for PLA residents-whether they would embrace the enlargement of NP including where they lived. Surprisingly, two thirds of respondents answered in the negative.

\section{Discussion and Conclusions}

The demographic figures of residents in both protected areas were different only in the category "age group". This characteristic used to be connected to perception of protected area and also place attachment. Some studies confirmed that younger people had more positive attitude towards protected areas (Najmanova, 2004; Liu, Ouyang, \& Miao, 2010), but others found no relationships between these quantities (Baral \& Heinen, 2007). In general, older people have stronger connection to the place of residence (Gorner, Najmanova, \& Cihar, 2012). In the case of this research, the economic situation influenced more the evaluation of the existence of a protected area. We detected significant differences in the employment in the private/public sector. PLA residents were less employed in the private sector and less involved in tourism services.

The second topic of this study focused on place attachment. This term could be defined as "affective link that people establish with specific settings, where they tend to remain and where they feel comfortable and safe" (Hernandez, Hidalgo, Salazar-Laplace, \& Hess, 2007). Place attachment could strongly affect the perception of nature protection activities in a region (Vorkinn \& Riese, 2001). The present study did not confirm this trend. Perception of home and community attachment also positively influenced residents' quality of life and it could have the same sense as economic benefits (Scheyvens, 1999). We recognised stronger place attachment in PLA. Locals had longer generation ties and more frequently stated they could not move away. This corresponded to the historic development of the region-almost all people living near the border (NP region) were displaced during the Cold war whereas people in the area of today's PLA stayed.

One of the most important findings of this study was the very low participation of PLA residents in the tourism industry. They were also weakly connected with PLA management decision-making processes. They had less information about NP and PLA Administration activities. Due to this, they more frequently evaluated negatively the existence of the Administration. They also evaluated nature conservation management as too strict despite the fact that PLA have lower conservation level than NP. Other studies (Dimitrakopoulos et al., 2010; Kim, 2009) demonstrated that locals perceive protected areas positively if they trust (and therefore know) the management of 
this region. People in PLA should be better informed, e. g. by means of a periodic newsletter issued by the Administration and distributed to each household. Apart from knowledge, similar values setting could also be important. In Sumava, especially, since establishing the NP, there have been controversies in forest management, particularly whether the National Park mission should include felling trees affected by the bark beetle. This management approach has changed from interventionist (cutting and removal of invaded tress) to natural (self-regeneration of the forest) (Petrova, Cihar, \& Bouzarovski, 2011).

People in both protected areas were well informed about ecological problems in the region. They reported the highest knowledge of a specific ecological problem from all the monitored protected areas in the Czech Republic. To compare, in Krkonose NP 57.1\% of locals knew about an environmental problem; in the Podyji NP this was $48.3 \%$ and in Novohradske hory nature park only $24.7 \%$ (Bartos \& Cihar, 2011). The most frequently mentioned ecological problem was bark beetle. The activities of the Administration against this pest could also influence the attitudes of locals towards this institution. Evaluation of the Administration of the neighbouring Bavarian Forest NP (Germany) by locals worsened in the mid 1980s when NP management left affected forests to self-regeneration. Residents perceived damaged forests as a "brake" in tourism development and they actively fought against NP enlargement in the 1990s (Ruschkowski \& Mayer, 2011). The situation on the Czech side of the same mountain looks better in this regard.

Significantly fewer respondents in NP chose the answer "the environmental conditions have become better". Most of the forests affected by bark beetle stand in NP area. Local perceptions are also influenced by the media image of NP. Newspapers often criticised the NP Administration for management of the park, especially for the poor condition of protected forest growth (Kusova, Tesitel, \& Bartos, 2005). Due to this fact, locals did not have to perceive environmental conditions on the basis of their own observations but by means of the media.

Most respondents, especially in PLA, were not concerned about the number of visitors in the region. Locals in PLA often wished tourism could increase in their region. One possibility is to move certain tourism facilities from NP to PLA. The natural potential of the landscape is similar to NP; the development, for example, of the water areas and rivers which are suitable for recreation and water sports (the Lipno reservoir and the Vltava, Otava and Uhlava rivers). There are some highly developed facilities for winter sports, as well as for fishing, hunting and other activities. The opportunities for agro-tourism are also growing. Locals in PLA also frequently mentioned the need for tourism infrastructure development. Enlargement of tourism into the broader area would, for this reason, increase the income of locals in PLA. It would improve the local perception of the protected area in the region, as demonstrated, for example, by Sekhar (2003).

This study also proved that there is very low local awareness of the existence of a biosphere reserve in the PLA region. Nevertheless, the existence of this type of protected area would be suitable advertising for the region primarily among foreign visitors. The PLA also offers better opportunities in new forms of tourism development like horse-riding, paragliding, in-line skating and Nordic walking. Prospective construction of new tourism facilities would increase the pressure on the local environment. On the other hand, revenues from the tourism industry would increase and this sustainable development would be a better alternative for the region than unsustainable use of the area (logging and gold mining near Kasperske Hory).

A better economic situation was detected in NP-more people benefited economically from the tourism and assessed job opportunities more positively. However, according to NP residents, the presence of tourists is more likely to or definitely raises the cost of living (services and shop prices) in comparison with other regions. In general, prices in shops in tourist areas are higher than prices in other regions due to high demand and low competition.

It is worth mentioning that the communities in the Sumava cannot be seen as a homogenous group. Focused on the NP, there were communities (e.g. Modrava, Prasily) that respected the existence of the NP (increasing interest of tourists, better socio-economic development). On the other hand, the communities with high unemployment (Borova Lada) perceived the existence of NP as very limiting. These results were also confirmed by the study of Nolte (2004).

Summed up, the outputs of this study should contribute to understanding local people's attitudes in Sumava region. According to this work, it is not possible to apply the results from regular monitoring of NP residents' opinions to the PLA area. Locals in PLA have different attitudes to tourism, economic situation and also in nature protection management. They are, just as locals in NP, supportive of protected areas and present relatively high levels of knowledge of environmental issues. However, environmental awareness, in comparison with NP residents, is not accompanied by active participation in the solution of environmental problems. PLA residents are deeply rooted in the territory (great part of them have longer generation ties here; they don't want to move 
out of the area at all) and perceive the NP as a challenge for the further development of the whole region. But they are very concerned about employment opportunities and they wish tourism increase in their region. Economic incentives and tools should be found to create advantages for these people (e. g. selling local products with eco-labels, involving locals as tourist guides). More effective management is required to attract tourists to visit PLA more frequently. One of the possibilities could be emphasizing the existence of Biosphere Reserve in the territory. BRs are not recognized as a legal category of protected area in the Czech Republic but as an international concept it could attract especially foreign visitors.

Moreover, some gaps were found in the level of communication between locals in PLA and NP/PLA Administration. Better communication mechanism between these subjects should be developed to share main ideas on how protected area can be viewed as a benefit. Regular meetings or working groups could be a good starting point to listen to each other. At the moment we mention the existence of Biosphere Reserve again - its main goal is to promote sustainable development in terms of participation of the NP/PLA Administration in the life of local people.

At the very end, there is a need for improving the standard of living of local people and increasing their pride in living in a protected area. It is a generally accepted fact that locals need to be educated, informed and encouraged to participate in the management and development of their region. If resident's interest were marginalized for a long period, they could adopt actions detrimental to the goal of conservation of the area.

\section{References}

Baral, N., \& Heinen, J. T. (2007). Resources use, conservation attitudes, management intervention and park-people relations in the Western Terai landscape of Nepal. Environmental Conservation, 34, 64-72. http://dx.doi.org/10.1017/S0376892907003670

Bartlett, C. Y., Maltali, T., Petro, G., \& Valentine, P. (2010). Policy implications of protected area discourse in the Pacific islands. Marine Policy, 34, 99-104. http://dx.doi.org/10.1016/j.marpol.2009.04.021

Bartos, L., \& Cihar, M. (2011). Socio Environmental Attitudes amongst the Inhabitants of Border Mountain Regions Close to the Former Iron Curtain: The Situation in the Czech Republic. Journal of Environmental Protection, 2, 609-619. http://dx.doi.org/10.4236/jep.2011.25070

Brandon, K., Gorenflo, L. J., Rodrigues, A. S. L., \& Waller, R. W. (2005). Reconciling biodiversity conservation, people, protected areas and agricultural suitability in Mexico. World Development, 33, 1403-1418. http://dx.doi.org/10.1016/j.worlddev.2004.10.005

Cihar, M., \& Trebicky, V. (1997). Analysis of the Monitoring of Recreational Activities in the Central Part of Sumava National Park. Final Report of the Research Project by the MoE, Prague, 1997.

Cihar, M., Stursa, J., \& Trebicky, V. (2002). Monitoring of Tourism in the Czech National parks. Proceedings Conference Monitoring and Management of Visitor Flows in Recreational and Protected Areas, Vienna.

Cihar, M., \& Stankova, J. (2006). Attitudes of stakeholders towards the Podyji/Thaya River Basin National Park in the Czech Republic. Journal of Environmental Management, 81, 273-285. http://dx.doi.org/10.1016/j.jenvman.2005.11.002

Cihar, M., Trebicky, V., \& Stankova, J. (2008). Stakeholder's monitoring and involvement: management option for Sumava NP. In A. Raschi, , \& S. Trampetti (Eds.), Proceedings Conference Monitoring and Management of Visitor Flows in Recreational and Protected Areas. Montecatini Terme, Italy, October 14-16, 2008.

Cudlinova, E., Lapka, M., \& Bartos, M. (1999). Problems of agriculture and landscape management as perceived by farmers of the Sumava Mountains (Czech Republic). Landscape and Urban Planning, 46, 71-82. http://dx.doi.org/10.1016/S0169-2046(99)00048-1

Czech Statistical Office. (2003). Statistical Yearbook of the Czech Republic 2003. 1st printing. Praha: CSU.

Dimitrakopoulos, P. G., Jones, N., Iosifides, T. Florokapi, I., Lasda, O., Paliouras, F., \& Evangelinos, K. I. (2010). Local attitudes on protected areas: Evidence from three Natura 2000 wetland sites in Greece. Journal of Environmental Management, 91, 1847-1854. http://dx.doi.org/10.1016/j.jenvman.2010.04.010

Freund, R. J., \& Wilson, W. J. (2003). Statistical Methods (2nd ed.). San Diego: Academic Press.

Garcia-Frapolli, E., Ramos-Fernandez, G., Galicia, E., \& Serrano, A. (2009). The complex reality of biodiversity conservation through Natural Protected Area policy: three cases from the Yucatan Peninsula, Mexico. Land Use Policy, 26, 715-722. http://dx.doi.org/10.1016/j.landusepol.2008.09.008 
Gorner, T., \& Cihar, M. (2012). Indicator System of Czech National Parks and Biosphere Reserves: Some developing trends in Sumava National Park. Silva Gabreta, 18, 49-58

Gorner, T., Najmanova K., \& Cihar, M. (2012). Changes in Local People's Perceptions of the Sumava National Park in the Czech Republic over a Ten Year Period (1998-2008). Sustainability, 4, 1354-1370. http://dx.doi.org/10.3390/su4061354

Hernandez B., Hidalgo M. C., Salazar-Laplace M. E., \& Hess S. (2007). Place attachment and place identity in natives and non-natives. Journal of Environmental Psychology, 27, 310-319. http://dx.doi.org/10.1016/j.jenvp.2007.06.003

IUCN. (1994). Guidelines for Protected Area Management Categories. Gland, Switzerland: IUCN.

Kim, T. G., (2009). Efficient management of marine resources in conflict: an empirical study of marine sand $\begin{array}{llll}\text { mining, Korea. Journal of Environmental Management, } & \text { 91, 78-86. }\end{array}$ http://dx.doi.org/10.1016/j.jenvman.2009.07.006

Kluvankova-Oravska, T., Chobotova, V., Banaszak, I., Slavikova, L., \& Trifunovova, S. (2009). From government to governance for biodiversity: The perspective of Central and Eastern European transition countries. Environmental Policy and Governance, 19, 186-196. http://dx.doi.org/10.1002/eet.508

Kusova, D., Bartos, M., \& Tesitel, J. (1999). Potential development of the right shore of Lipno Lake area: Comparision of landscape and urban planning documentation with ideas of local inhabitants. Silva Gabreta, 3, 217-228.

Kusova, D., Tesitel, J., \& Bartos, M. (2005). The media image of the relationship between nature protection and socio-economic development in selected Protected Landscape Areas. Silva Gabreta, 11, 123-134.

Kusova, D., Tesitel, J., Matejka, K., \& Bartos, M. (2008). Biosphere reserves-an attempt to form sustainable landscape (A case study of three biosphere reserves in the Czech Republic). Landscape and Urban Planning, 81, 187-197. http://dx.doi.org/10.1016/j.landurbplan.2007.06.006

Liu, J., Ouyang, Z., \& Miao, H. (2010). Environmental attitudes of stakeholders and their perceptions regarding protected area-community conflicts: A case study in China. Journal of Environmental Management, 91, 2254-2262. http://dx.doi.org/10.1016/j.jenvman.2010.06.007

Najmanova, K. (2004). Monitoring of attitudes of residents in selected centers of KRNAP and Sumava NP, Diploma thesis, FoS UK Prague [In Czech].

Nolte, B. (2004). Sustainable tourism in Biosphere reserves of East Central European Countries: Case studies from Slovakia, Hungary and the Czech Republic. In T. Sievanen, J. Erkkonen, J. Jokimäki, J. Saarinen, S. Tuuletie, \& E. Virtanen (Eds.), Policies, Methods and Tools for Visitor Management. Proceedings of the Second International Conference on Monitoring and Management of Visitor Flows in Recreational and Protected Areas, Rovaniemi, Finnland.

Petrosillo, I., Zaccarelli, N., Semeraro, T., \& Zurlini, G. (2009). The effectiveness of different conservation policies on the security of natural capital. Landscape and Urban Planning, 89, 49-56. http://dx.doi.org/10.1016/j.landurbplan.2008.10.003

Petrova, S., Cihar, M., \& Bouzarovski, S. (2011). Local nuances in the perception of nature protection and place attachment: A tale of two parks. Area, 43, 327-335. http://dx.doi.org/10.1111/j.1475-4762.2011.00995.x

Pimbert, M. L., \& Pretty, J. N. (1997). Parks people and professionals: putting "participation" into protected-area management. In K. B. Ghimire \& M. P. Pimbert (Eds.), Social Change and Conservation. Environmental Politics and Impacts of National Parks and Protected Areas. London: Earthscan.

Ruschkowski, E., \& Mayer, M. (2011). From Conflict to Partnership? Interactions between Protected Areas, Local Communities and Operators of Tourism Enterprises in Two German National Park Regions. Journal of Tourism and Leisure Studies, 17(2), 147-181.

Sekhar, N. U. (2003). Local people's attitudes towards conservation and wildlife tourism around Sariska Tiger $\begin{array}{llll}\text { Reserve, India. Journal of Environmental Management, 69, 339-347. } & \text {. }\end{array}$ http://dx.doi.org/10.1016/j.jenvman.2003.09.002

Sewell, W. R. D. (1973). Broadening the approach to evaluation in resource management decision-making. Journal of Environmental Management, 1, 33-60.

Stursa, J. (2002). Impacts of Tourism Load on the Mountain Environment (A Case Study of the Krkonoše 
Mountains National Park-the Czech Republic), Proceedings Conference Monitoring and Management of Visitor Flows in Recreational and Protected Areas, Vienna.

Suchy, J. (2002). Determination of actual attendance and its annual dynamics in Krkonose Biospheric Reserve. Final report of the research project VaV/610/8/00, Prague [In Czech].

Tesitel, J. (2005). Participative management of protected areas-the key to minimalize conflicts between biodiverzity protection and socio-economic development of local communities. Final report of the research project VaV/610/3/03, Ceske Budejovice [In Czech].

Vorkinn, M., \& Riese, H. (2001). Environmental concern in a local context: The significance of place attachment. Environment and Behavior, 33, 249-263. http://dx.doi.org/10.1177/00139160121972972

Wallner, A., Bauer, N., \& Hunziker, M. (2007). Perceptions and evaluations of biosphere reserves by local residents in Switzerland and Ukraine. Landscape and Urban Planning, 83, $104-114$. http://dx.doi.org/10.1016/j.landurbplan.2007.03.006

$\mathrm{Xu}$, J., Chen, L., Lu, Y., \& Fu, B. (2006). Local people's perceptions as a decision support for protected area management in Wolong Biosphere Reserve, China. Journal of Environmental Management, 78, $362-372$. http://dx.doi.org/10.1016/j.jenvman.2005.05.003 